\title{
UTILIZANDO RESÍDUOS COMO FERRAMENTA PARA EDUCAÇÃO AMBIENTAL E O ENSINO DA QUÍMICA
}

\section{ARTIGO ORIGINAL}

MIRANDA, Igor de Sousa ${ }^{1}$

SANTOS, Cleidison da Silva²

MENDES, Manoel Henrique de Souza ${ }^{3}$

MIRANDA, Adriele Mayara Soares ${ }^{4}$

MIRANDA, Igor de Sousa. Et al. Utilizando resíduos como ferramenta para educação ambiental e o ensino da química. Revista Científica Multidisciplinar Núcleo do Conhecimento. Ano 04, Ed. 07, Vol. 10, pp. 70-86. Julho de 2019. ISSN: 2448-0959

\section{RESUMO}

O presente trabalho tem como principal objetivo produzir gesso e de tinta ecológica com resíduos de cascas de ovos. Para mais, sabemos que a reutilização destes resíduos tem como objetivo obter novos materiais, logo, torna se uma ferramenta imprescindível aos alunos na reflexão sobre questões ambientais na sua própria comunidade. Isto, desperta na criança uma maior capacidade de avaliar a importância da preservação do meio ambiente para saúde da sociedade ao qual ele está inserido. Todo desenvolvimento do estudo gira em torno da conscientização sobre o meio ambiente e o ensino da química como ferramenta estimuladora. Para tanto, organizouse no campus do IFPA da cidade de Óbidos-PA, um programa de atividades com

\footnotetext{
${ }^{1}$ Mestrado em Química pela Universidade Federal do Pará.

2 Doutorando em Educação: Universidade Nacional de Rosário.

${ }^{3}$ Graduando em licenciatura Química pela Universidade Federal do Pará.

${ }^{4}$ Mestrado em Biociências pela Universidade Federal do Oeste do Pará.
} 
todos os alunos da $2^{0}$ série do ensino médio do instituto. Elaboramos o projeto junto à comunidade e as coletas foram efetuadas durante um período de uma semana, sendo comparada a quantidade de lixo produzida pelas residências e por pontos comerciais. Os resíduos de casca de ovos foram tratados e usados como matéria prima para produção de gesso e de tinta ecológica. A comunidade teve a oportunidade de participar da semana de meio ambiente produzida pelo IFPA, onde foram demonstrados os resultados dos trabalhos dos alunos. O resultado final do trabalho foi satisfatório, pois o objetivo de produzir materiais industriais pelo uso de cascas de ovos como uma proposta para ensinar educação ambiental e química foi alcançado. Os resultados nas avaliações escritas demostraram que o conceito dos conteúdos efetivamente foi fixado e entendido pelos alunos, desta forma o aprendizado foi mais significativo uma vez que estimulou a criatividade entre os alunos e a pesquisa como uma ferramenta para o aprendizado da química e a formação do cidadão com consciência ambiental e social.

Palavras-Chave: Educação Ambiental, gesso, tinta ecológica, Química, experimentação.

\section{INTRODUÇÃO}

Os Parâmetros Curriculares Nacionais (PCN's) de Química do ensino médio, basicamente estabelecem uma relação comum entre as ciências que compõem a área, esta relação consiste na investigação da natureza e o desenvolvimento tecnológico como um parâmetro que a escola deve compartilhar e articular como uma linguagem comum o qual crie uma cultura cientifica capaz de produzir um conhecimento escolar relacionado com conceitos do cotidiano e do universo cultural desta ciência.

Mesmo existindo esses parâmetros que orientam a forma de se articular um conteúdo dentro da disciplina de química, as dificuldades da relação do ensino-aprendizagem de química vem tornando-se alvo de debate na atualidade, pois, a maioria dos alunos não consegue relacionar os conteúdos ensinados com o seu cotidiano (PAZ, et al. 2010). 
Seguindo a ideia comum que a educação tem por base, que é a formação do cidadão com consciência social e ambiental, podemos destacar a ciência química e a educação ambiental como ferramentas estimuladoras para conscientização de problemas ambientais, formando neste contexto cidadãos com maior consciência ambiental e social.

Para SANTOS, et al (2011) o aprendizado da química como instrumento para a educação ambiental pode transformar o ensino em um processo de permanente valorização das diversas formas de conhecimento com o objetivo de formar um cidadão que tenha consciência local e planetária. Nesse contexto, o autor propôs utilizar o lixo e reciclagem como tema motivador para a abordagem dos conteúdos químicos relacionados com alguns temas sociais e ambientais. Seguindo esta temática, o conteúdo repassado propiciou ao aluno uma percepção cientifica e crítica da problemática apresentada, tornando a aprendizagem mais dinâmica e significativa.

Durante a pesquisa, os alunos selecionaram uma problemática ambiental que vem aumentando nos últimos anos, o qual também foi trabalhado como tema motivador para o ensino de ciências, este tema, esta relacionado com a industrialização e o aumento no consumo de ovos no mundo todo, pois em decorrência disso, o número de resíduos das cascas de ovos tem aumentado expressivamente nos últimos anos. Segundo FREIRE et al. (2006) só no Brasil são geradas aproximadamente 120.000 toneladas por ano de casca de ovo, dos quais a maior parte destes é despejado no meio ambiente de forma inadequada, contribuindo assim para o aumento nos impactos ambientais.

Considerando essa problemática, diversos autores vêm estudando a composição dos resíduos da casca do ovo e diversas formas de reutilizá-las como fonte de matériaprima para indústrias. Por exemplo, FREIRE e colaboradores (2008), ao realizar um estudo sobre a casca de ovo, notou por meio de análises de Difratograma de Raio-X que este resíduo é predominantemente constituído de carbonato de cálcio, componente essencial na formulação do silicato de cálcio e principal fonte para produção industrial de óxido de cálcio. O mesmo autor ainda cita que, através de análises termogravimétricas, foi possível prever que o carbonato de cálcio presente 
na casca do ovo se decompõe em óxido de cálcio basicamente em temperatura igual ou acima de $800^{\circ} \mathrm{C}$.

Segundo VIEIRA (2004), o pó de carbonato de cálcio, obtido a partir da casca de ovo, pode atuar como agente na remoção de metais pesados em meio aquoso, e ainda RODRIGUES et al. (2015) apresentou a possibilidade de se reutilizar a casca de ovo como fonte de $\mathrm{CaCO}_{3}$ e $\mathrm{CaO}$, em especial na indústria farmacêutica que poderia produzir fármacos para pessoas os quais tem problemas de saúde relacionados à falta de cálcio no organismo. Outra possibilidade também citada é a aplicação destes resíduos em hortas ou terras destinadas ao cultivo de plantações, visando a correção do $\mathrm{pH}$ de solos muito ácido.

Segundo SOARES (2005), misturando-se carbonato de cálcio com ácido sulfúrico nas devidas proporções, é possível se obter o sulfato de cálcio, este que é o principal constituinte do gesso, muito utilizado no ramo da medicina e do artesanato. Apesar da abundância de matéria prima para fabricação de gesso nas indústrias, a ideia de reutilizar resíduos como uma proposta para produção deste material se torna uma alternativa significativamente atraente, uma vez que um dos assuntos causadores de discussão entre os gestores e a sociedade são a geração e a destinação final de resíduos, logo a utilização das cascas de ovos significa uma redução da disposição destes resíduos com elevado potencial poluidores em aterros sanitários.

O óxido de cálcio, que pode ser gerado pela calcinação de resíduos de casca de ovos, é um sólido branco, pouco solúvel em água à temperatura ambiente e gera soluções com alta alcalinidade, de pH em torno de 12,8. A chamada água de cal é uma solução saturada de óxido de cálcio. Na indústria de tinta o $\mathrm{CaO}$ é utilizado principalmente na produção de tinta cal, geralmente usada para pintura, também conhecida como caiação, é utilizada desde a antiguidade para corrigir imperfeições de paredes (MORAES et al, 2015). O uso de tintas cal provenientes do CaO produzido pela calcinação de resíduos de cascas de ovos, poderia garantir produtos mais baratos e processos químicos mais seguros e ambientalmente limpos (GIULIO, 2007). 
Conforme tudo o que foi exposto, a ideia de se relacionar o ensino de áreas da química com a educação ambiental torna-se bastante atraente, pois essa aproximação de problemas relacionados ao descarte inadequado de resíduos e a reutilização de resíduos com o objetivo de se obter novos materiais acaba proporcionando aos alunos, que acompanharem o projeto, a possibilidade de refleti sobre questões ambientais na sua própria comunidade, despertando na criança uma maior capacidade de avaliar a importância da preservação do meio ambiente para saúde da sociedade ao qual ele esta inserido. Todo conhecimento adquirido na escola pode alimentar ainda a ideia de que o aluno pode mudar a realidade de sua comunidade de forma positiva. A produção de materiais provenientes de resíduos da casca de ovos pode também proporcionar ao aluno e a comunidade uma oportunidade de novas formas de empreendimento e desenvolvimento de tecnologias mais limpas em termos ambientais.

O trabalho sobre a produção de materiais a partir de resíduos de casca de ovos foi desenvolvido no Instituto Federal do Pará (IFPA) campus de Óbidos-PA. O principal objetivo do trabalho foi proporcionar aos alunos a oportunidade de discussão sobre temas relacionados com o meio ambiente utilizando a química como uma ferramenta para reutilizar resíduos despejado de forma inapropriada e desordenada na natureza, minimizando assim muitos impactos ambientais gerados pelo descarte inadequado de materiais os quais podem ter utilidade como produto reciclado.

Em um panorama pedagógico, as atividades desenvolvidas no trabalho podem surgir como uma ferramenta que possibilite o aprendizado de conceitos de química de forma contextualizada e relacionada à temática da educação ambiental, fornecendo desta maneira, um embasamento teórico e prático para que o aluno possa desenvolver conceitos críticos e científicos sobre o tema envolvido no projeto.

Os principais conceitos trabalhados durante o desenvolvimento da pesquisa foram: meio ambiente e poluição ambiental, soluções químicas, estequiometria, reações químicas, equilíbrio químico, termoquímica, educação ambiental e desenvolvimento sustentável. Como grande parte do conteúdo apresentado estava inserido na grade 
curricular das turmas do $2^{\circ}$ ano, estas foram selecionados para elaboração da pesquisa, totalizando um total de 3 turmas com aproximadamente 40 alunos em cada.

\section{MATERIAIS E MÉTODOS}

Toda elaboração do trabalho foi desenvolvida tendo como principal foco a conscientização sobre o meio ambiente e o ensino da química como ferramenta estimuladora para produção de tecnologias os quais ajudem a garantir a diminuição de resíduos de lixo na natureza. Para tanto, organizou-se no campus do IFPA da cidade de Óbidos-PA, um programa de atividades com todos os alunos da $2^{\circ}$ série do ensino médio do instituto, tendo como principal foco as turmas dos cursos integrados de técnicos em meio ambiente e floresta, visto que são as quais iram formar profissionais ligados diretamente com a área de meio ambiente.

Primeiramente, para começo das atividades foi desenvolvido um levantamento de informações, onde os alunos foram incentivados a pesquisar sobre diversos assuntos relacionados com o meio ambiente, incluindo leis e tecnologias existentes para reciclagem de materiais. Para tanto, foram formadas equipes, em cada turma, compostas com 5 indivíduos, a finalidade da pesquisa era coletar o máximo de informação possível sobre o tema, e desta maneira foi possível traçar uma relação entre o estudo da química e o meio ambiente. Através do levantamento feito, todas as equipes apresentaram um tema relacionado com a química e o meio ambiente, estes temas foram postos em votação pelas turmas. Os alunos de todas as turmas escolheram e criaram um tema comum, denominado pelos próprios alunos de: "Utilização de resíduos da casca de ovos de galinha como uma proposta para produção de produtos industriais a baixo custo". A partir deste tema foi elaborado um projeto pedagógico o qual deveria atender as necessidades das aulas teóricas e práticas relacionando a química e o tema ambiental escolhido.

\subsection{PROJETO DIDÁTICO-PEDAGÓGICO}

Utilização de resíduos da casca de ovos de galinha como uma proposta para produção de produtos industriais a baixo custo 


\subsubsection{OBJETIVO GERAL}

Utilizar processos químicos de reutilização de resíduos como uma ferramenta para o ensino da química e educação ambiental.

\subsubsection{OBJETIVOS ESPECÍFICOS}

- Estimular o aluno a compreender conceitos básicos de química os quais estejam relacionados com o processo de reutilização de resíduos da casca de ovos;

- Promover a conscientização ambiental entre escola e sociedade;

- Produzir uma tinta ecológica e gesso utilizando como matéria prima resíduos de casca de ovo de galinha;

- Produção e análise de rendimento do óxido de cálcio, produzidos através de calcinação de resíduos de ovos lavados;

- Produção e análise de rendimento do sulfato de cálcio, produzido através da reação de ácido sulfúrico e a casca do ovo triturado e lavado;

- Utilizar os conhecimentos empregados no trabalho para estimular o aprendizado de disciplinas básicas, que tenham relação com educação ambiental, nos diversos cursos oferecidos pelo instituto.

- Utilizar conceitos básicos de química para promover a educação ambiental.

\subsubsection{CONTEÚDO}

- Educação Ambiental

- Soluções químicas

- Cinética química

- Estequiometria

- Reações químicas

Turmas: Todas as séries do $2^{\circ}$ ano técnico integrado ao ensino médio

Tempo estimado: 3 meses 
Material necessário:

- Bequer

- Estufa

- Álcool $70 \%$

- Água sanitária

- Água destilada

- Agitador magnético

- Ácido sulfúrico

- Cola PVA

- Mufla

- Balança

- Vidro de relógio

- Liquidificador

- Cascas de ovos trituradas

\subsubsection{DESENVOLVIMENTO}

O desenvolvimento do trabalho foi elaborado em 3 etapas. Na primeira etapa buscouse efetuar um levantamento teórico sobre os assuntos relacionados ao tema escolhido pelos alunos e a química ambiental; já a segunda etapa consistiu no método de preparo de materiais pelo uso de resíduos de casca do ovo; e a última etapa foi a de avaliação com o objetivo de verificar o aprendizado dos alunos. Cada etapa esta descrita abaixo:

- Etapa 1: Neste primeiro momento serão levantadas várias questões relacionadas ao meio ambiente e o lixo urbano, incentivando os alunos a refletirem sobre impactos ambientais e leis elaboradas por gestores públicos no município e no planeta. Após o debate e pesquisa feita pelos alunos, serão ministradas aulas de química relacionando o tema selecionado com a disciplina, mostrando ao discente a importância do conhecimento da química para se promover gestão de resíduos e produção de materiais que ajudem a diminuir impactos ambientais regionais e planetários. $\mathrm{O}$ objetivo final desta 
etapa será desenvolver no aluno um espírito critico, cientifico e social sobre todos os assuntos relacionados com o meio ambiente.

- Etapa 2: Neste passo, os alunos serão divididos em grupos e incentivados a catalogar a quantidade de lixo e resíduos de ovos de galinha que podem ser coletados em suas residências e em pontos de refeição próximos de suas casas com objetivo de serem usados como matéria prima na operação do trabalho. Para incentivar a coleta, os grupos devem distribuir nos estabelecimentos e lares, panfletos falando sobre conscientização ambiental. Durante a entrega dos panfletos, cada grupo também efetuará uma apresentação oral sobre o trabalho e sua importância na comunidade. Além dos panfletos, também serão distribuídos na comunidade recipientes para coleta de cascas de ovos. Após a coleta, os alunos serão levados ao laboratório para fabricar os materiais a partir de resíduos da casca de ovos de galinha conforme protocolo elaborado.

- Preparação E Limpeza Do Resíduo

Para preparação e limpeza dos resíduos da casca de ovos, primeiramente será feito a lavagem do material utilizando-se água sanitária. Após lavagem das cascas, será efetuada a secagem do material em uma estufa com temperatura medindo $80 \stackrel{\circ}{\circ}$, durante o processo de secagem o material deverá ficar confinado na estufa por 24 horas. Depois de efetuado estes procedimentos, serão feitos à retirada da membrana interna da casca do ovo, sendo seguido da moagem da casca. Ao final do processo, será feito a pesagem do material em balança analítica e os dados serão armazenados para posteriores comparações em análises de rendimento (RODRIGUES, 2017).

- Produção de óxido de cálcio

Para produção do óxido de cálcio, as cascas de ovos trituradas e limpas serão submetidas ao processo de calcinação em mufla por um tempo de $1 \mathrm{~h}$ em temperatura de $800^{\circ} \mathrm{C}$.

- Obtenção do Sulfato de cálcio (Gesso) 
Para obtenção do sulfato de cálcio, primeiramente será separado em um béquer uma quantidade de $200 \mathrm{~g}$ de casca de ovo já previamente tratado e triturado. Em seguida, sobre a amostra, será adicionado $280 \mathrm{ml}$ de solução de ácido sulfúrico 8 Molar, o qual ficará sobre constante agitação em agitador magnético por um tempo de 30 minutos. Depois de terminado o tempo de reação, o material resultante será filtrado e levado para secagem em estufa regulada em $105^{\circ} \mathrm{C}$ por um tempo de 24 horas.

\section{- Preparo da tinta}

Para preparo da tinta, serão misturados em um recipiente $200 \mathrm{~g}$ de óxido de cálcio, produzido a partir da casca do ovo, e $400 \mathrm{ml}$ de água. A mistura será agitada durante 10 minutos e deixada em repouso por mais 10 minutos. Posteriormente, sobre a solução deve ser adicionado $100 \mathrm{ml}$ de cola PVA, a mistura será agitada novamente e levada para teste.

- Etapa 3: Depois de já formado o produto final, serão levantadas novamente questões relacionadas a educação ambiental, o papel social de cada pessoa como cidadão e como podemos aplicar o conhecimento cientifico como ferramenta para diminuir os impactos ambientais em uma sociedade. Esta etapa final tem basicamente dois momentos avaliativos, o primeiro consiste em observar o desenvolvimento de cada equipe, analisando o desempenho e desenvoltura dos alunos na apresentação e explicação do trabalho durante suas apresentações no evento da Semana do Meio Ambiente ofertado pelo IFPA campus Óbidos-PA. No segundo momento desta etapa, será passada uma avaliação teórica para cada aluno individualmente, onde o conteúdo principal será baseado nas etapas práticas de preparação do projeto e sua relação com os tópicos da química tais como: Estequiometria, Soluções químicas, reações química e Cinética química.

\subsubsection{PRODUTO FINAL}

- Seminários, na escola e na comunidade, apresentando os problemas e as soluções possíveis para o lixo; 
- Uma amostra apresentada na Semana do Meio Ambiente, mostrando para toda comunidade a produção da tinta ecológica e do gesso como materiais industriais obtidos pelo uso de resíduos da casca de ovos de galinhas.

\section{RESULTADOS E DISCUSSÃO}

$\mathrm{Na}$ etapa de coleta de resíduos, inicialmente os alunos efetuaram um levantamento sobre a quantidade de resíduos gerados em residências e em pontos comerciais próximo de suas casas. O resultado obtido foi que cada residência produzia aproximadamente $600 \mathrm{~g}$ de lixo por dia, dos quais $24 \mathrm{~g}$ eram resíduos de casca de ovos, e os estabelecimentos comerciais (restaurantes e lanchonetes) geravam aproximadamente $4 \mathrm{Kg}$ de lixo por dia, dos quais cerca de $800 \mathrm{~g}$ eram resíduos de casca de ovos. Os resultados da coleta total efetuada pelos alunos durante uma semana foram reunidos na Tabela 1, na referida tabela podemos observar que a quantidade de lixo produzida por um estabelecimento comercial é equivalente a aproximadamente a uma quantidade de lixo produzida por 7 dias de uma residência, neste sentido as politicas publicas referentes a coleta seletiva, poderiam começar os incentivos de coleta com os restaurantes e lanchonetes do município. Conforme o levantamento feito, $100 \%$ da população, que participou do trabalho, não fazia seleção do lixo, sendo o material orgânico misturado com todo tipo de material reciclável ou não. Nesta etapa, podemos observar que apesar da mídia efetuar uma campanha sobre a importância de se fazer a separação do lixo, muitos moradores não tem nenhum costume em separar o lixo, a maioria dos cidadãos alegam que os agentes de catação não fazem distinção do lixo e mesmo o morador tendo separado o lixo, no final tudo é misturado dentro do caminhão de coleta, não havendo por parte da prefeitura um incentivo para coleta seletiva. 
Tabela 1. Quantidade de lixo e resíduo de casca de ovo produzido por cada residência e por cada estabelecimento comercial.

\begin{tabular}{|l|l|l|}
\hline Local de coleta & $\begin{array}{l}\text { Quantidade média de } \\
\text { Lixo produzido em } \mathbf{7} \\
\text { dias }\end{array}$ & $\begin{array}{l}\text { Quantidade média de Resíduos } \\
\text { de casca de ovos produzida em } \\
\mathbf{7} \text { dias }\end{array}$ \\
\hline $\begin{array}{l}\text { Residência } \\
\text { Restaurante e/ou } \\
\text { lanchonetes }\end{array}$ & $28 \mathrm{Kg}$ & $1,5 \mathrm{Kg}$ \\
\hline
\end{tabular}

Fonte: Autor

Após a etapa de levantamento de informações, foram selecionados 24 pontos para coleta, sendo 12 residenciais e 12 comerciais. Cada grupo ficou responsável por coletar e explicar a importância da coleta nos pontos selecionados, para tanto eram feitas apresentações utilizando o folheto intitulado de: "Meio Ambiente - A problemática do Lixo".

Figura 1. Logomarca para o evento da semana de meio ambiente e a imagem dos grupos divididos para elaboração do projeto.

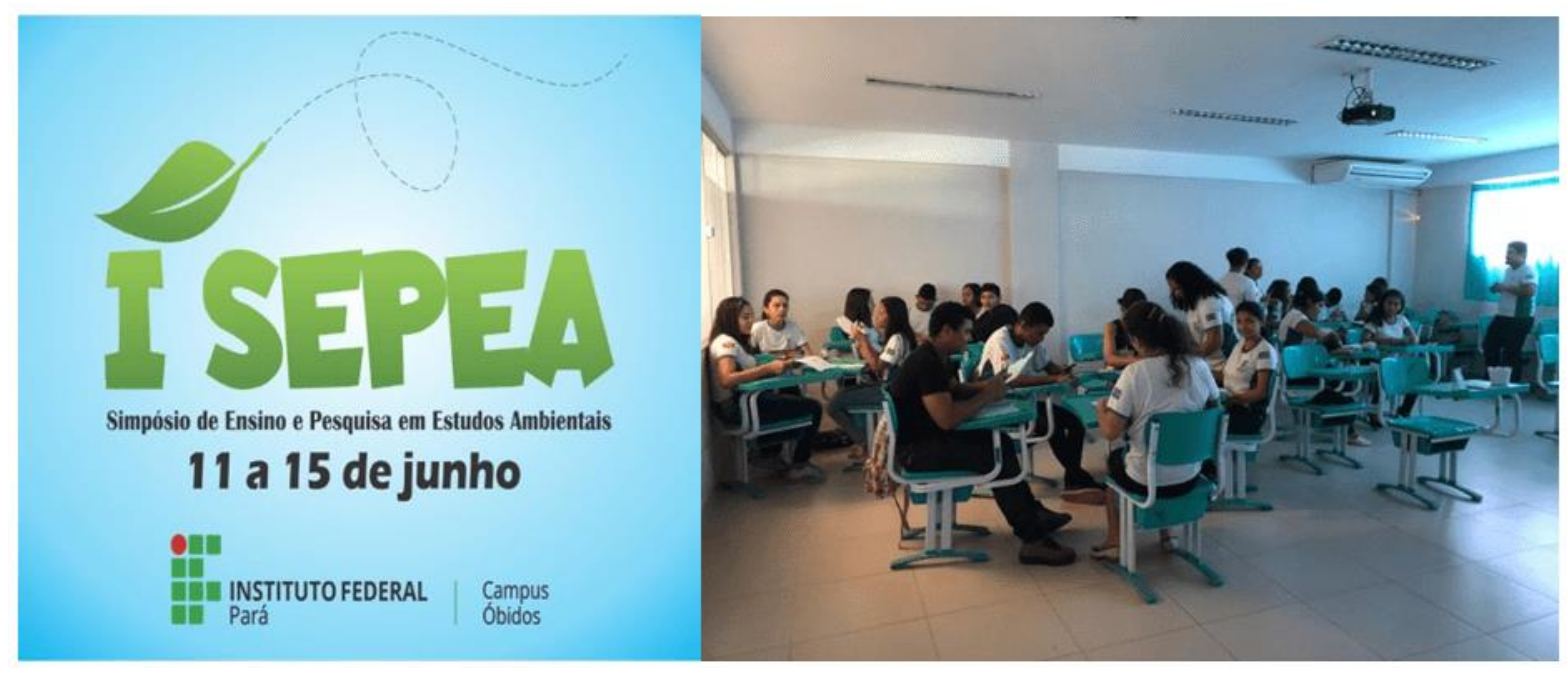

( Fonte: Autor) 
Durante toda apresentação dos alunos nas residências e nos pontos comerciais, eram repassadas informações sobre educação ambiental e sobre problemas ambientais causados pelo descarte inadequado do lixo, além disso, foi distribuído na comunidade, recipientes de plásticos para separação e posterior coleta das cascas de ovos de galinha. Tanto os moradores quanto os funcionários dos estabelecimentos comerciais, se propuseram a participar do trabalho e em acompanhar o resultado do processo durante o encontro de meio ambiente que ocorreria durante o evento da semana do meio ambiente do IFPA campus Óbidos-PA. Os resultados do processo de reutilização também serviram como um instrumento divulgador e incentivador para participação dos pais e da comunidade no evento sobre o meio ambiente ofertado pelo IFPA em parceria com a Universidade Federal do Oeste do Pará (UFOPA). No evento, os alunos apresentaram os resultados e explicaram o processo mostrando cada etapa para produção da tinta ecológica e do gesso, sendo distribuída entre os ouvintes uma pequena quantidade do material produzido. Neste momento, o docente também participou do evento e avaliou a apresentação dos grupos no trabalho. Foi observado que todos os alunos participaram durante a explicação do projeto e também que todos explicaram os processos químicos e físicos corretamente, mostrando que o levantamento de dados efetuado pelos grupos realmente serviu como instrumento para o aprendizado de química e de educação ambiental. 
Figura 2. Imagem dos grupos separando o material coletado e efetuando a limpeza das cascas de ovos triturada.

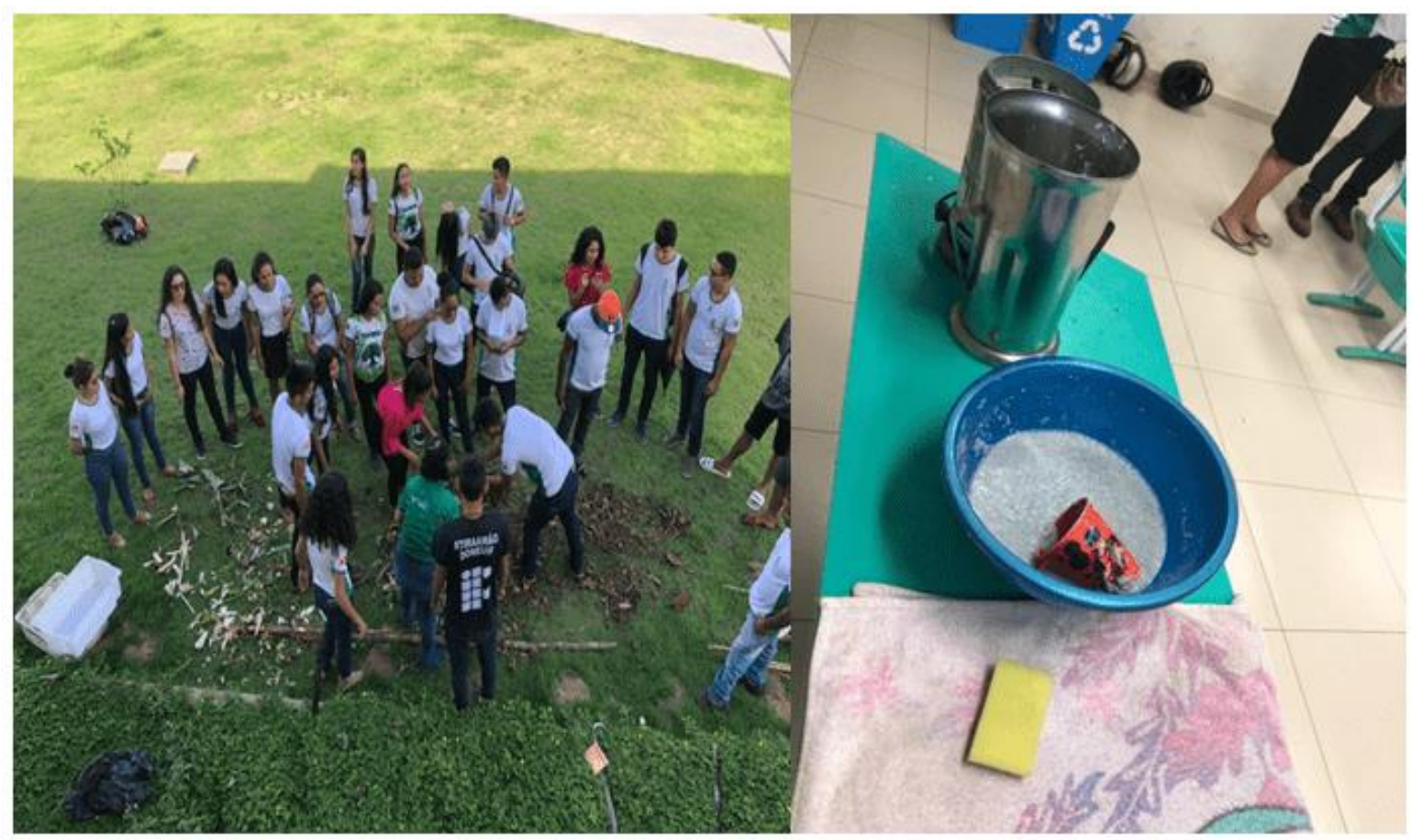

(Fonte: Autor)

PAZ e colaboradores (2010) analisaram o processo ensino-aprendizagem de química da $2^{\circ}$ série do ensino médio de algumas escolas públicas. Os dados levantados pelos autores mostraram que aproximadamente $70 \%$ dos alunos desta série tem grande dificuldade em aprender a disciplina por terem problemas relacionados com cálculos, e ainda aproximadamente $30 \%$ tem problemas relacionados à falta de aulas práticas. Conforme os autores, a metodologia utilizada pelo professor é um motivo marcante para isso, pois acaba dando ênfase a memorização de fórmulas, e desta maneira, priorizam-se os cálculos e desvaloriza-se a experimentação e a construção do conhecimento científico, fazendo com que os alunos tenham muita dificuldade em aprender a disciplina nesta etapa.

Seguindo a realidade e a problemática relacionada com os cálculos químicos, durante o trabalho os alunos foram sempre incentivados a efetuarem todos os cálculos por meio de observações e experimentações, por exemplo, para produção do óxido de 
cálcio foi observado por cada grupo que em média $1 \mathrm{Kg}$ de resíduo da casca de ovo triturado, produzia, após o processo de calcinação, cerca de $480 \mathrm{~g}$ de material (oxido de cálcio), com estes resultados, foi possível que os alunos encontrassem o rendimento da reação através da relação estequiométrica entre $0 \mathrm{CaCO}_{3}$ e $\mathrm{CaO}$ conforme equação 1:

$\mathrm{CaCO}_{3}(\mathrm{~s}){ }^{\Delta} \mathrm{CaO}(\mathrm{s})+\mathrm{CO}_{2}(\mathrm{~g})$ Equação (1)

(Peso molecular $\mathrm{CaCO}_{3}: 100 \mathrm{~g}$ ) (Peso molecular $\mathrm{CaO}: 56 \mathrm{~g}$ )

Teórico: $(1 \mathrm{~kg} \mathrm{CaCO} 3)(560 \mathrm{~g} \mathrm{CaO})$

Experimental: (Casca de ovo triturado: $1 \mathrm{Kg}$ ) (Material produzido: $480 \mathrm{~g}$ )

Teoricamente e sem levar em consideração a pureza do material, com aproximadamente $1 \mathrm{Kg}$ de resíduo de casca de ovo (composto basicamente de $\mathrm{CaCO}_{3}$ ) seria possível obter aproximadamente $560 \mathrm{~g}$ de material calcinado (composto basicamente de $\mathrm{CaO}$ ). Por meio das informações e pelos resultados encontrados no experimento foi demonstrado por parte dos alunos que a referida reação teve um rendimento de aproximadamente $86 \%$.

Na produção do gesso a partir do resíduo da casca de ovo triturado, primeiramente os grupos tiveram que calcular a quantidade de ácido Sulfúrico necessária para prepara $300 \mathrm{ml}$ de uma solução com concentração 8 Molar. Com os resultados obtidos, o técnico de laboratório do instituto manuseio todo o procedimento e os discentes tiveram a oportunidade de acompanhar todo o processo de produção da solução, em virtude de questões de segurança e falta de material de proteção pessoal para os alunos, esta etapa se limitou apenas na observação. O objetivo desta atividade foi basicamente demonstrar a produção de soluções químicas no laboratório. Depois de produzida a solução, foi efetuada a mistura entre o resíduo da casca de ovo e a solução, neste processo não foi fornecido aos alunos à reação envolvida e cada grupo teve que escrever a possível equação entre a mistura composta basicamente de $\mathrm{CaCO}_{3}$ (resíduo triturado) e $\mathrm{H}_{2} \mathrm{SO}_{4}$ (Solução Ácida). Todos os grupos conseguiram 
encontrar corretamente a equação envolvida no processo e também efetuou de forma correta o balanceamento da mesma conforme demostrado abaixo (equação 2):

$\mathrm{CaCO}_{3}(\mathrm{~s})+\mathrm{H}_{2} \mathrm{SO}_{4}(\mathrm{aq}) \mathrm{CaSO}_{4}(\mathrm{~s})+\mathrm{H}_{2} \mathrm{O}(\mathrm{l})+\mathrm{CO}_{2}(\mathrm{~g})$ Equação (2)

Durante a etapa de produção do material, foi possível observar que praticamente todos os alunos queriam estar envoltos no projeto, isso demonstra que a experimentação tem um papel muito importante na construção e no incentivo do conhecimento para disciplina de química. $O$ défice de atenção durante as explicações de cada parte do conteúdo foi mínimo e a grande dificuldade da relação dos cálculos matemáticos com a disciplina foram baixos. Foi observado durante o trabalho que a maioria dos alunos tinha conhecimento básico de matemática, porém uma grande dificuldade em aplicar as equações em um problema de química. Ficou evidente, durante $o$ andamento da pesquisa, que com a observação e a experimentação fica muito mais prático e fácil o aluno aplicar os cálculos para um devido fim em uma experiência no laboratório, desta maneira a disciplina não fica basicamente restrita apenas em equações e cálculos decorativos e pouco atraentes.

Muitos autores fortificam a ideia do melhor aprendizado em química obtida por meio da experimentação, por exemplo, SILVA JÚNIOR (2016) expõe uma reflexão sobre a experimentação no ensino da química. Para o autor, a utilização de experimentação possibilita o aluno vivenciar situações reais que são apresentadas nos conceitos de química, e dessa maneira o aluno tende a participar mais na aula e ao mesmo tempo Ihe permite relacionar a teoria com a prática. $O$ autor ainda acrescenta que as atividades práticas na química tem como proposito desenvolver os alunos de forma mais efetiva no processo de aprendizagem, por isso é preciso criar novas formas que fomentem de forma investigativa o ensino de química e motive os alunos em aprenderem a elaborar hipóteses, coletar e analisar dados e estruturarem suas próprias conclusões a fim de aplicá-las na sociedade da qual ele faz parte.

SILVA (2016) admite que os processos de aprendizagem de conteúdos conceituais e procedimentais são enriquecidos por meio de atividades investigativas, esses tipos de atividade, independente do ambiente onde são realizadas, proporcionam e promovem 
um papel mais ativo aos alunos no desenvolver das aulas, logo a construção do conhecimento é muito maior por meio de observações e investigações quando comparados com uma aula meramente teórica.

No trabalho desenvolvido, aproximadamente $90 \%$ de todos os alunos envolvidos conseguiram obter nota maior ou igual à média da escola na avaliação escrita (teórica). Isso demonstra que o uso dos recursos didático-pedagógicos envolvido nas atividades influenciou e motivou o processo de ensino-aprendizagem, pois o uso da química como ferramenta para produção de materiais estimulou a prática e a experimentação cientifica dos conteúdos envolvidos nas atividades. A avaliação foi dividida em 15 questões dissertativas, sendo 5 sobre meio ambiente e 10 de química abrangendo os conteúdos de solução química, cinética química, estequiometria e reações químicas. O objetivo principal desta etapa avaliativa foi observar se houve fixação da parte teórica do assunto pelos alunos, como a grande maioria obteve sucesso durante a avaliação escrita, conclui-se que o uso dos recursos pedagógicos utilizados serviu como uma ferramenta para o ensino da disciplina ministrada. Após o trabalho, a média total em termos de nota dos alunos na disciplina com relações há anos anteriores, praticamente aumentou em $80 \%$ e o número de alunos retidos para recuperação chegou a aproximadamente zero.

\section{CONCLUSÃO}

O trabalho e o levantamento de informações efetuado pelos alunos serviram como instrumento estimulador para busca de conhecimento relacionada ao meio ambiente, incentivou a pesquisa sobre a problemática do lixo, desenvolvendo nos discentes uma visão crítica sobre a forma como a sociedade atual vive e o quanto cada ser humano efetivamente se preocupa com essa temática.

Os dados encontrados pelos alunos no experimento de fabricação de materiais pelo uso de resíduos de casca de ovos de galinha se apresentaram como um excelente método para motivar o ensino aprendizado da química. A ideia de demonstrar a importância e a finalidade do uso de cálculos matemáticos na fabricação de materiais gerou uma diminuição nos altos índices de dificuldade dos alunos em relacionar o uso 
de cálculos com a química. O que possivelmente pode ter contribuído para esse sucesso foi utilizar os cálculos para uma finalidade prática, mostrando para o aluno que as fórmulas utilizadas também fazem parte da experimentação, e desta forma os cálculos tem uma objetividade, uma vez que são essenciais para se começar e finalizar o experimento.

O uso do projeto acabou também incentivando muito a participação da comunidade no evento da semana do meio ambiente ofertado pelo IFPA, pois durante a apresentação do trabalho, muitos moradores tiveram a oportunidade de expor de que forma participaram para a execução do projeto e como o projeto influenciou no ponto de vista de cada morador sobre a temática do meio ambiente e a questão do lixo urbano.

O resultado final do trabalho foi satisfatório, pois o objetivo de produzir materiais industriais pelo uso de cascas de ovos como uma proposta para ensinar educação ambiental e química foi alcançado. Os resultados nas avaliações escritas demostraram que o conceito dos conteúdos efetivamente foi fixado e entendido pelos alunos, desta forma o aprendizado foi mais significativo uma vez que estimulou a criatividade entre os alunos e a pesquisa como uma ferramenta para o aprendizado da química e a formação do cidadão com consciência ambiental e social.

Embora o trabalho tenha ajudado a conscientizar parte da comunidade e alunos, novos trabalhos sobre educação ambiental devem ser produzidos e ao mesmo tempo utilizados para formação do cidadão e do aprendizado das ciências como um todo.

\section{REFERÊNCIAS}

BRASIL. Ministério da Educação, Secretaria de Educação Média e Tecnológica. Parâmetros Curriculares Nacionais: Ensino Médio. Brasília: 1997.

FREIRE, M.N.; HOLANDA, J.N.F. Characterization of avian eggshell waste aiming its use in a ceramic wall tile paste . Cerâmica. vol.52, n.324, p 240-244. ISSN 0366-6913 / 2006. 
FREIRE, M.N.; SOUSA, S.J.G.; HOLANDA, J.N.F. Using eggs hell in red wall tiles. Waste and Resource Management, v. 161, p. 23-27 / 2008.

GIULIO G.D. Setor de tintas cresce, inova e foca na questão ambiental. Inovação Uniemp v.3 n.6 Campinas dic. 2007.

MORAES, M. A. B.; AFONSO, J. C.; GOMES, L. M.B. Análise química de carbonatos de cálcio fabricados entre 1902 e 2002. Revista de Química Industrial 2015, 746, 27.

PAZ, G. L.;NETO, C. O. C ; OLIVEIRA, M. L. . Dificuldades no ensino aprendizagem de Química no Ensino Médio em algumas escolas públicas da região sudeste de Teresina. In: $8^{\circ}$ Simpósio Brasileiro de Educação Química, 2010, Natal - RN.

RODRIGUES, A. S.; ÁVILA, S. G. Caracterização Físico-Química da Casca de Ovo de Galinha e Utilização como Fonte para Produção Compostos de Cálcio. Revista Virtual Química. 2017, 9 (2), 596-607.

RODRIGUES, A. S.; ÁVILA, S. G. Caracterização Físico-Química da Casca de Ovo de Galinha e Utilização como Fonte para Produção Compostos de Cálcio. Revista Virtual Química. 2017, 9 (2), 596-607.

SANTOS, P. T. A.; DIAS, J.; LIMA, V. E.; OLIVEIRA, M. J.; NETO, L. J. A.; CELESTINO, V. Q. Lixo e reciclagem como tema motivador no ensino de química. Eclética Química. São Paulo, $36,2011$.

SILVA JÚNIOR, E. A.; PARREIRA, G. G. Reflexões sobre a importância da experimentação no ensino da Química no ensino médio. Revista Tecnia. vol. 1, n. 1, 2016.

SILVA, V. G. A Importância da experimentação no ensino de química e ciências. Trabalho de Conclusão de Curso. Faculdade de ciências - Departamento de química, Universidade Estadual Paulista - UNESP, Bauru-SP. 42f, 2016. 
SOARES, J. P.; Estudo Microestrutural do Gesso-Alfa Produzido pelo Processo Hidrotérmico e Calcinação a Seco e sua Influência nas Propriedades Mecânicas Pós Hidratação. Recife, 2005. Dissertação (Mestrado em Engenharia Mecânica), Universidade Federal de Pernambuco, 2005.

VIEIRA, C. M. F.; SOUZA, E. T. A.; MONTEIRO, S. N. Efeito da incorporação de chamote no processamento e microestrutura de cerâmica vermelha. Cerâmica. vol. 50, n.315, p. 254-260 / 2004. ISSN 0366-6913.

Enviado: Julho, 2019.

Aprovado: Julho, 2019. 